\title{
On Design Thinking, Bullshit, and Innovation
}

\author{
Rodrigo Hernández-Ramírez \\ UNIDCOM-IADE, Universidade Europeia, \\ Lisbon, Portugal \\ rodrigo.ramirez@universidadeeuropeia.pt
}

\begin{abstract}
Design thinking (DT) has been widely promoted as a powerful approach for systematically achieving innovation, particularly in the world of management. Recently, however, some critical voices from design and science \& technology studies have called bullshit on DT, accusing it instead of distorting and trivialising design methods and processes to serve purely commercial goals. Through an analysis of the recent history of design research and an overview of some (philosophical) accounts on the concept of "bullshit", this paper shows that at least some of the criticism holds. However, it argues that a truly fruitful critique of DT needs to go beyond simple derision. Ultimately, this paper suggests that perhaps we should steer away from the idea that there is a designerly way of thinking, and focus instead on showing how designers, being "doers", create maker's knowledge. Designers, educators, managers, and anyone interested in understanding why design goes beyond a simple methodology perhaps might be interested in this account.
\end{abstract}

\section{KEYWORDS}

Design thinking; Design methodology; Bullshit; Innovation; Maker's knowledge; Philosophy of design.

\section{ARTICLE INFO}

Received: 08 October 2018

Accepted: 30 November 2018

Published: 18 December 2018

https://dx.doi.org/10.7559/citarj.v10i3.555

\section{1 | INTRODUCTION}

Throughout the last decade, design thinking (DT) has been heavily promoted as an effective system to tackle all kinds of problems, from conceiving new products to providing drinking water to small communities in the Global South. Addressing problems the way designers (supposedly) doadvocates of DT suggest-is not only an excellent approach to innovation but also one that is guided by human needs. DT has become popular within management and financial circles; but after almost fifty years of neoliberalisation, the idioms and practices of that culture have penetrated every domain of human activity. Consequently, DT has found its way into many different kinds of public and private organisations with its most vocal promoter being the "d.school" based in Stanford University.

Despite its seemingly well-intentioned selling points, some critical voices have called DT into question, or rather, have called bullshit on DT, implying that it is little more than another jargon-filled management fad driven by mere commercialisation. Admittedly, the world of management has been known to endorse almost any "philosophy" that offers to give its practitioners some competitive business or administrative advantage, regardless of the soundness of its principles. However, the idea that designing is not just a discipline (but rather a distinct epistemic system), and that tackling highly complex problems is its raison d'être, has been endorsed by some of the most influential design scholars for years. 
DT advocates characterise it as a "human-centered, creative, iterative, and practical approach to finding the best ideas and ultimate solutions" (Brown, 2008, p. 92); as an unparalleled method to "innovate". They contend that even though DT is firmly grounded on tried and tested design methods and processes used by (some) designers to tackle design issues, the methodology is easily portable and can be executed by any (expediently trained) person in any given context. Some DT enthusiasts (Dunne \& Martin, 2006) in business schools have even suggested incorporating said methodology as part of their core curricula. However, by far the most touted virtue of DT is how it fosters empathy amongst its practitioners and, consequently, enables them to gain a better understanding of those at the receiving end of any DT-guided undertaking (e.g., clients, users, or employees).

Conversely, detractors of design thinking contend that it distorts design methods and innovation. They claim it is reductive and uncritical and that it focuses on simplistic processes rather than on concrete outputs (Jen, 2017). They also claim design thinking trivialises how innovations come about and promotes a "skewed" understanding of the role design plays in such processes (Vinsel, 2017). In the end, for these critics, design thinking merely condenses a formulaic and naive view of the design process, using buzzwords and corporate jargon, for the benefit of non-designers. Moreover, since such an audience is mainly located within the world of management, it follows that design thinking has less to do with design or social change and more with business (Vinsel, 2017).

This paper shows that the better part of the above criticism stands to truth, since some advocates of (a particular strain of) DT do engage in some types of bullshitting, but argues that the judgement cannot be generalised. The main reasons are that neither bullshit nor DT are consensually defined or even homogeneous concepts. Therefore, this paper argues that a more fruitful critique of DT requires going beyond the name-calling by promoting a broader and deeper understanding of design but also of innovation and technological change.

The first section offers a general description of the historical context in which DT emerged and grew in popularity. Next comes a summary of the main arguments held by detractors of DT, followed by a survey of three different (philosophical) characterisations of bullshit. This is followed by an in-depth discussion of DT in light of the previous accounts. Ultimately, this paper suggests that perhaps we should steer away from the idea that there is a designerly way of thinking, regard it as a brand, and focus instead on showing why designers, like other "doers", create maker's knowledge.

\section{2 | NEOLIBERALISM, CHANGE FOR THE SAKE OF CHANGE, AND DESIGN}

Throughout the last half-century, most countries in the world yielded to the neoliberal program, undergoing profound social transformations. Neoliberalisation, i.e., the process whereby radical market rule is aggressively encouraged and assisted by the political class (see Peck, 2010, p. xii), is not only a socioeconomic but also a cultural change. Neoliberal doctrine is overtly antagonistic towards government oversight, which it denounces as hopelessly bureaucratic. Nonetheless, as anthropologist David Graeber notes, if anything has been shown in the past decades is that most policies intended for curtailing government interference engendered more procedures and regulations (Graeber, 2015, p. 9). Neoliberalism, it turns out, is far from being the antithesis of regulation but rather "a self-contradictory form of regulation-in-denial" (Peck, 2010, p. xiii) that breeds even more bureaucracy.

Neoliberalism enabled business organisations to claim more of the roles that were for a long time assumed to be government prerogatives (e.g., education, healthcare, policing) thus displacing the nation-state as the dominant political and cultural institutions of societies. In the process, business, and entrepreneurs began more aggressively portraying themselves as the primary agents of social change; management came to be mystified all the while the socioeconomic and historical circumstances behind neoliberalisation faded into the background (see LoRusso, 2017). Gradually, as Graeber also notes, public and private power ended up merging into a single entity leading to a state of "total bureaucratization" (2015, pp. 17-18) wherein government and private bureaucracies became indistinguishable. Deregulation and privatisation enabled the idiosyncrasies, worldview, and practices of the corporate culture to spread to every area of human activity where "people gather to discuss the 
allocation of resources of any kind" (2015, p. 21). The hitherto alien techniques of corporate bureaucracy, its obsession with productivity and its penchant for jargon-in particular, "creativity" and "innovation"-have come to shape how we work, live, and play.

While this state of affairs amounts to a bureaucratic takeover, managers, the protagonists behind this process, do not think of themselves as bureaucrats. Instead, they would like to portray themselves as potentially creative agents of change. Even though most of what they do involves devising new procedures, regulations and metrics to improve the "accountability" or "productivity" of the people under their command. Usually, this requires finding new ways to quantify the unquantifiable for the sake of systematising otherwise intuitive processes and facilitating automation. Total bureaucratisation thus comes disguised in the language of change; change that has gone from being the means for an end to an end in itself. The reinvention of innovation as an indispensable process for human development and wellbeing coincided with this change in values and practices (see Godin, 2008).

Design is an activity and a practice concerned with creating plans for new things; it has come to be seen as a natural ally to fulfil the endless need to innovate. For many people in the world of management design methodologies appear to be recent adoptions, but the relationship between management and design has a long history, with some influential design theorists being also management theorists-prime examples being Donald Schön and Herbert A. Simon. Such circumstances have enabled the creators of a very specific design process (i.e., "design thinking") to promote it as a kind of magic bullet to consistently come up with innovations. The new managerial class, whose job is to permanently create "hollow change" and who require a constant "supply of new management fads and fashions" (Spicer, 2017) have enthusiastically embraced it.

\section{3 | CALLING BULLSHIT ON DESIGN THINKING}

In a recent talk, Natasha Jen (2017), a graphic designer, design educator, and partner in Pentagram design studio, denounced the "complete lack of criticism" that the "design community" has shown against design thinking (DT) [1]. She showed how conducting a simple Google search on DT results in endless variations of the same motives: a diagram depicting a colour-coded five-step process accompanied by hyped business jargon or a group of enthusiastic people using Post-it notes. For Jen, although the five-step process gives the impression of being a thoroughly reasonable design methodology, it lacks a crucial component explicitly built into it: critical feedback. As a professional designer, Jen contends that feedback (however uncomfortable) and evaluation throughout the entire design process are the only means to improve any potential solution to a design problem.

Jen also objects to the way DT has seemingly limited the design tools to a single medium: Post-it notes. She sees this as a token of the extent to which the DT advocates have downplayed the complexity of design as a professional practice. Jen is also aware of the historical roots of design practice and the academic lineage of design research. She notes that what eventually became DT initially emerged as a rigorous framework in industrial design but has since then been appropriated by other areas of design. Mostly, Jen is concerned about the way hyper-optimistic, but ultimately meaningless business jargon has supplanted serious reflection about design in general. Unimpressed by some design solutions created following DT methodology, Jen objects that a focus on the process rather than on the results seriously compromises the quality of the output. The way she sees it, genuinely successful design solutions (such as those created by Charles and Ray Eames) always involve a tangible "evidence" of the results. Therefore, she challenges DT enthusiasts to prove, not procedurally but through concrete results, how and why their methodology can live up to the hype. Finally, Jen offers her definition of design thinking, portraying it as something that:

packages the designer's way [of thinking] by working for a non-designer audience by codifying their processes into a prescriptive, step-by-step approach to creative problem solving, claiming that it can be applied by anyone to any problems. (Jen, 2017, min 4:14)

More recently, Jen (2018) doubled down on her criticism, noting how the more she has continued to try to wrap her head around DT, the more 
outrageous it seems. Besides reaffirming her initial objections, Jen now highlights the "simplistic equation" that DT advocates claim that exists between DT methodology, creativity and innovation; as well as the way they reify innovation, treating it as more than an attribute or quality. Furthermore, Jen is appalled by way DT portrays design as a kind of "beast" that can be suddenly unleashed [2], thus obscuring the fact that designing is, in fact, a process; something that develops over a certain timespan. Consequently, DT promises quick, effortless results bordering the kind of instant but ultimately hollow satisfaction that fast food offers. For Jen, this fast food logic becomes dangerous when one looks at the way DT approaches education. DT training seems to be entirely based on bootcamps and fast short courses that give the impression that students can learn design methodology, "get good at it", simply by following their curricula.

In a recent article, Lee Vinsel (2017), STS professor at Virginia Tech, builds a case against DT along the same lines as Jen, although in a significantly more caustic style, comparing the cultural influence of DT to late-stage syphilis infection. Acknowledging his lack of expertise in design methodologies, Vinsel focuses instead on the way DT advocates portray "innovation" - which he derisively qualifies as a "lipstick-on-a-pig" conception. Vinsel, like Jen, is concerned by the way DT understands education; he is dismayed by the suggestion (apparently advanced by some of its advocates) that DT could eventually become the foundation of "the new liberal arts" [3]. Vinsel is unimpressed by such proposition and by the possibility that DT could be incorporated at secondary and undergraduate level education as a new core discipline. Mainly because DT encourages the notion that the ultimate goal of education is "social innovation", a proposition which Vinsel qualifies as an "adolescent conception of culture". Vinsel summarises his critique by arguing that DT is not about design, the liberal arts, or meaningful innovation, but about commercialisation and "making all education a shallow form of business education".

For all their bluntness, Jen's and Vinsel's criticisms make valid points: openness to feedback is crucial for any creative enterprise and in design tangible outcomes are the only means to judge how well a given solution works. Furthermore, innovation is a nebulous, relational concept, and shallowness is the least desirable feature one should associate with education. Nonetheless, name-calling and pungent commentaries only go so far when it comes to building fruitful criticism-not to mention that bullshit, like innovation, is seldomly defined. The following section provides an overview of the (philosophical) criteria to determine whether something might be called bullshit or not, and why. The goal here is not to attempt to settle once and for all what bullshit means but to provide a stepping stone for advancing our discussion and understanding of DT.

\section{4 | THREE WAYS TO UNDERSTAND BULLSHIT}

In everyday language, "bullshit" is unmistakably an expletive. Bullshit and bullshitters have been fairly common in human societies for a conceivably long time. However, in the mid-1980s, Harry Frankfurt noticed how little attention philosophers had paid to this phenomenon, and thus decided to turn it into a subject of serious philosophical enquiry. Originally published as an essay in 1986 and re-edited two decades later as a book, Frankfurt's On Bullshit is the seminal work on the study of this phenomenon [4]. Frankfurt begins his conceptual analysis by dissecting Max Black's (1982, p. 23) own characterisation of "humbug" as (a deliberate) "deceptive misrepresentation... of somebody's thoughts, feelings, or attitudes". Frankfurt notes that humbug might share some qualities with bullshit (namely, the intentional misrepresentation of one's intentions), but he argues that Black's account is not sufficiently adequate nor accurate for describing "the essential character of bullshit" (2005, p. 18). This essence, Frankfurt insists, lies in a lack of concern for the truth; in the bullshitter's utmost "indifference to how things really are" (2005, pp. 33-34).

Humbug, like lying, is intentionally deceptive and insincere, but bullshit does not need to be false. This feature is what according to Frankfurt makes bullshit more culturally tolerable but also more ethically dangerous. Liars deliberately conceal the truth; what they hide is their attempt to lead their audience "away from a correct apprehension of reality". In this sense, liars know (and care) about the distinction between true and false information. By crafting falsities, liars are "responding" to and - to such extent - being "respectful of the truth".

Conversely, a bullshitter does not "care whether the things he says describe reality correctly". Bullshitters 
merely select, or "make up", information to suit their purposes (2005, pp. 55-56). Whereas a liar intentionally rejects "the authority of the truth", the bullshitter does not even acknowledge its existence. This omission makes bullshit "a greater enemy of the truth than lies" $(2005$, p. 61). It follows that in Frankfurt's account, the intention-and hence, the mental state-of a person is the crucial factor in determining whether what he or she is saying can be qualified as bullshit.

Frankfurt's view, however, has been challenged. In his essay, Deeper Into Bullshit, G.A. Cohen argues that Frankfurt's "activity-centred" definition is "too narrow" (2002, p. 337). "Frankfurt-bullshit", Cohen notes, is "just one flower in the lush garden of bullshit"; it is exclusively concerned with "ordinary life", leaving out, for example, the type of bullshit "that appears in academic works" (2002, p. 323). Cohen calls into question Frankfurt's insistence on the "essential" features of bullshit because such definition is not characterising the utterance itself, but the bullshitter's (morally questionable) state of mind. Cohen further questions Frankfurt's sharp distinction between bullshitting and lying. He argues that "it is neither necessary nor sufficient for every kind of bullshit" to be uttered by someone indifferent to the truth (2002, p. 332). An honest, truth abiding person could be, unbeknownst to her, uttering bullshit out of ignorance-or due to self-deception or even for charitable reasons, as we will see below. Cohen thus suggests a different criterion for identifying bullshit: "unclarifiable unclarity". Here, bullshit is discourse "that is not only obscure but which cannot be rendered unobscure", since any attempt to clarify it yields "something that isn't recognisable as a version of what was said (2002, pp. 332-333). Cohen thus places the blame not on the bullshitter but on bullshit itself. In this way, what is criticised is the product of bullshitting, which is visible, rather than the process that led to it, which is opaque (2002, p. 336). In summary, in Cohen's "output-centred" approach, unmasking a bullshitter does not require proving that he did not care about the truth, but showing that his utterance, even when reformulated, cannot make sense.

A third way to determine what may be qualified as bullshit stands mid-ground between Frankfurt's and Cohen's accounts. Philosopher Scott Kimbrough (2006) agrees that Frankfurt's definition leaves out unintentional bullshitting, but he agrees with him that bullshit results from a lack of connection with the truth. Kimbrough objects that we should not and perhaps cannot eradicate bullshit from human discourse because it would compromise many aspects of our social interactions. Bullshitting, whether we like it or not, is crucial for civility and politeness, at least in most Western societies. Frankfurt calls bullshit whenever the truth is disregarded, but while his definition is correct, it is also true that people often engage in bullshitting to avoid confrontation, to protect someone's feelings, or to socialise. In such instances, there might be justifiable reasons to disregard the truth. Kimbrough thus contends that "bullshit must be recognised for what it is and restricted and sanctioned to truly justifiable uses" (2006, sec. 5). Since the mere act of justifying why bullshit is preferable over truth in any given situation implies being able to distinguish between the two.

Kimbrough, nonetheless, refuses to endorse Cohen's output-centred criterion, insofar as rejecting the product implies rejecting the process behind it and hence the people responsible for it. Kimbrough notes that Cohen's attempt to separate the bull from the shit (so to speak) cannot stand, for "it is just not possible to call bullshit courteously" (2006, sec. 4). Qualifying something as bullshit means marginalising it and excluding it from serious discussion. Many people call bullshit not because they feel the truth is being disregarded, but because the so-called bullshit threatens their beliefs or values. Frankfurt's truth-centric definition remains valid because it circumvents such potential relativism by introducing Truth as a clause. Kimbrough's way to reconcile Cohen's insight that bullshit can be produced unintentionally while retaining Frankfurt's truth-centric criteria is by shifting away from psychological processes (states of mind) and towards "methodology". In this manner, the way bullshit is produced continues to be the determinant factor to identify it, but the utterer's motivation measured against her circumstances become the moral compass to judge it. Put in other terms, bullshit is the result of adopting "lame methods of justification, whether intentionally, blamelessly, or as a result of self-deception" to disregard the truth.

The following section will discuss the heterogeneity of design before addressing Vinsel's and Jen's 
objections against design thinking in light of the definition of bullshit provided in Section 4 .

\section{5 | DISCUSSION}

\subsection{ON WHY DT IS NOT HOMOGENEOUS}

Design is a "quintessentially modern" (Parsons, 2015, sec. 1.4) discipline that only established itself as a genuinely independent practice in the twentieth century. In the Western world, the exact origins of design remain contested [5], but we do know they lie sometime in the early Industrial Revolutionalthough its philosophical roots stretch back to the Renaissance (Buchanan, 2001). Over the past 250 years, Design went from being a trade activity that displaced "tradition-based craft" (Parsons, 2015) to a "segmented profession" to a "field for technical research" (Buchanan, 1992) and a scholarly discipline. Theoretical reflection on the broader socioeconomic and cultural role of design first emerged in the late nineteenth century with the Arts and Crafts movement. The Interwar period brought schools such as De Stijl and the Bauhaus, and the Postwar witnessed the rise and fall of the Ulm School of Design (Hochschule für Gestaltung UIm), which played a central role in the rise of the design methods movement during the 1960s-70s. The last decades of the twentieth century brought design studies, and the early 2000s the prefiguration of "philosophy of design" - see Galle (2002) and Love (2000) for a short overview [6]. Discussing at length each one of the stages of development of Design is beyond the aims and possibilities of this paper. Nonetheless, we could partially conclude that since the early twentieth-century Design has come to be understood not only as a professional discipline but as a full independent epistemic system concerned (mainly) with the built environment.

The exact origins of the term "design thinking" are difficult to trace, a quick search in Google's Ngram Viewer shows its usage first began to take off in the 1940s and grew more or less steadily throughout the following decades. In 1987, Peter Rowe published Design Thinking, a book that aimed to show how Architecture, Design, and urban planning are manifestations of the same strategy of inquiry. By the early 1990s, the incidence of the term shows a steep rise. This growth may be attributed to a series of academic conferences organised around this time - such as the "Design Thinking Research" symposia, as well as to various publications on DT by theorists such as Nigel Cross and Kees Dorst (see Cross, 2001).

By the early 2000s, Todd Kelley and Tim Brown from the design consultancy agency IDEO branded their in-house "problem-solving" process as "design thinking" [7] and began promoting it as a new comprehensive strategy to foster "innovation". By 2006 Kelley and his colleagues secured a generous donation from the German software businessman Hasso Plattner to establish the "Stanford d.school" (Miller, 2018). Officially called the "Hasso Plattner Institute of Design", the d.school became the de facto think tank of what henceforth I will be referring to as IDEO-DT. Through the d.school, Kelley and his associates have successfully popularised the (synecdochical) misconception that the idiom, practices, love of Post-it notes and, above all, the five-step process that emerged at IDEO are the essence of DT in general. In other words, they have failed to clarify that design methodologies and processes are anything but homogeneous.

The core assumption behind the very idea of "design thinking" is that designing calls for a particular mindset: a "third way" (Brown, 2009) of regarding and dealing with problems, which stands in-between intuition and (logical) rationality [8]. The design theorist L. Bruce Archer argued, for example, that "there exists a designerly way of thinking and communicating" that is different from those of the sciences and the humanities "when applied to its own kinds of problems" (1979, p. 17) [9]. Archer contended the traditional division of scholarly subjects along these two axes "leaves out too much", in particular, competencies concerned with "material culture" (1979, p. 18), and hence called for the institution of a "third area" in education. Design "with a big D" would have equal standing in education alongside Science and the Humanities but it would comprise "the collected body of practical knowledge based upon sensibility, invention, validation and implementation" (1979, p. 20). Furthermore, whereas the "essential language[s]" of Science and the Humanities are, respectively, (mathematical) notations and natural language, Design would rely on models. In short, according to this view, Design is a distinctive "approach to knowledge" and "a manner of knowing" that is irreducible to either corner of the conventional Western epistemological framework. 
Building upon and expanding Archer's ideas, Nigel Cross promoted the notion of a "designerly way of knowing" in a series of homonymous publications. There, Cross further characterised Design as a discipline concerned with the "man-made [sic] world" that values "practicality, ingenuity, empathy, and a concern for 'appropriateness'” (1982, pp. 221-222); which normally deals with "ill-defined, ill-structured, or 'wicked'” problems (1982, p. 224). Cross defends the epistemic autonomy of Design, urging scholars and practitioners to "avoid swamping our design research with ...cultures imported either from the sciences or the arts" (2001, p. 55) [10]. Over the years he has sought to understand how and why designers think the way they do, and to show that their epistemic stance is, in fact, a manifestation of a fundamental aspect of human intelligence in general (2006). More recently, echoing the title of Rowe's (1991) own book, Cross (2011) published a book titled Design Thinking. There, he aimed to document and articulate the basic cognitive and creative skills that designers supposedly employ, characterising them as a kind of "natural intelligence" [11] (Cross, 2011, Chapter 8) that is available to anyone willing to develop it.

Given the previous account, it is clear that by actively promoting a synecdochical identification between IDEO-DT and the historical understanding of "design thinking" the d.school and its partners have hijacked the meaning of this term. Most designers would agree that their particular approaches to solving design problems do not have to resemble the methodology and process described by IDEO-DT to work. Design methodologies and processes may exist by the hundreds, and some of them share a few characteristics. However, suggesting that one of them is the most adequate for every circumstance would be preposterous simply because it goes against the very idea of what designing means, i.e., creating plans. To paraphrase Bryan Lawson $(2005$, p. 48) the very idea that design activities occur in a given order or that they represent identifiable separate events is questionable. Both designing and the thinking involved in it are heterogeneous. IDEO-DT is equal parts design methodology (mostly inherited from interaction design and industrial design), and management theories [12] (with a high dose of Esalen's "human potential" ideas). It is just one amongst many competing approaches to problemsolving in design - and if we lend credit to Natasha
Jen (2018), not a particularly effective or imaginative one.

\subsection{THE EPISTEMOLOGICAL PROBLEM OF DESIGN}

At this point, it should be clear that Jen's (and Vinsel's) criticism is directed not at the broader theorisation of design as a third epistemic system, but specifically at IDEO-DT. Recapitulating, Jen's first objection concerns the absence of an explicit critical component in the five stages to which IDEODT reduced the design process. This particular point is informed by her decades as a professional designer who understands that creative improvements often come at the cost of relentless (and often harsh) feedback. Jen's objection is not trivial; it is intimately linked to one of Design's most crucial problems; one that has arguably stood behind every attempt to formalise and systematise design methods and processes: how can a designer be confident that what she creates will duly serve its purpose? That her solution will work [13]? The problem is epistemological; it asks what kind of knowledge designers require to create adequate solutions for any given problem?

Design is a projective and poetic activity. It does not seek explanation and prediction (like the sciences) nor insightful understanding (like art and the humanities), but rather to change and (re)construct aspects of the world. Although definitions may vary, Design is more or less characterised as an activity concerned with "the conception and planning of the artificial', to borrow Richard Buchanan's (1992, p. 14) words. Alternatively:

"[...]design is the intentional solution of a problem, by the creation of plans for a new sort of thing, where the plans would not be immediately seen, by a reasonable person, as an inadequate solution." (Parsons, 2015, sec. 1.1)

To paraphrase Parsons (2015, secs 2.1-2.2), designers attempt to create plans for novel devices or processes that solve fundamentally practical problems. And they do so by taking into consideration the functional, symbolic, aesthetic, mediating, and even socio-political implications of their creations. In Design, there are no a priori judgements. Whether such fundamentally creative process can be effectively broken down into "objective" stages and procedures or instead will 
forever remain governed by the mysteries of intuition is the crux of the tension between design science and other approaches to design research.

Jen's pragmatic way of overcoming this epistemological dilemma is by focusing on tangible "evidence", on concrete assessable outcomes, rather than to endlessly ponder which might be the best solution to a given design problem. Conversely, and this answers another of Jen's objections, the goal of IDEO-DT is precisely to focus on the process. IDEO-DT is (purportedly) a method for coming up with "innovative" solutions, however outrageous they might initially seem. Because it promotes a (dubious) kind of epistemological anarchism, IDEO-DT deliberately excludes criticism [14]; here, "thinking-out-of-the-box" means anything goes, preferably if it involves a solution that has not been tried before.

Interestingly, Jen's and IDEO-DT's understanding of where attention should be placed (either on the outcome or the process, respectively) overlap with the ways Cohen and Frankfurt (respectively) identify Bullshit. For Jen, the design process is too complex to be reduced to well-demarcated steps. Thus, the only potentially objective judgement we can make has to be done on the final object. Similarly, Cohen argues the processes that lead to bullshit are opaque and not necessarily intentional. Bullshit ought to be judged as a standalone product by its (lack of) clarity.

Conversely, IDEO-DT emphasises the "how" rather than the "what". The result is secondary because what matters is the process. Frankfurt's moral criteria for identifying bullshit also fits that description. Whether this connection can tell us something about ethics or epistemology, could perhaps be addressed elsewhere.

\subsection{INNOVATION AND DESIGN AS A LIBERAL ART}

The last of Jen's objections against IDEO-DT concern the way its advocates reify "innovation" and promote a "fast-food" logic of (design) education. Her views overlap with Vinsel's criticism. Drawing on his scholarly knowledge of the history, dynamics, and socio-economic impact of technological change, Vinsel contends that "there is no evidence that IDEO, design thinking, or the d.school have contributed to deep [sociotechnical] change". He is particularly critical of the "superficial" way in which organisations such as IDEO employ the very term "innovation". Indeed, a simple exploratory reading of IDEO-DT literature shows that innovation is used extensively as a noun, verb, adjective, and more. However, finding anything even remotely similar to a definition of this term proves remarkably difficult. Consequently, it is perhaps best to assume that, "innovation" is used by IDEO-DT advocates as a slightly fancier substitute for (technological) "change".

As a concept, innovation has a long and not so illustrious history, since before the nineteenth century it had a mostly pejorative meaning. The contemporary English word "innovation" comes from late thirteenth century French, which itself comes from the Latin term innovo (renewal or make change). Innovo descends from the Greek term kainotomia, which derives from kainos (new), and meant "cutting fresh into" or "making new". Eventually, it was the metaphorical use of kainotomia that gave innovation its contemporary sense (see Godin, 2014, 2015). In the late eighteenth century innovation began to be conflated with "imagination" and (creative) combinationmainly by Romanticism - but it remained, for the most part, an obscure term. In the twentieth century, Joseph Schumpeter rehabilitated and endowed innovation with its contemporary economic meaning of commercialised invention (Godin, 2014, p. 15).

The contemporary view of innovation (the idea that it is the panacea for every problem) is symptomatic of the ways we have come to understand human progress and well-being. It is a manifestation of the shift in sensibilities concerning which human activities and practices are most beneficial for society at large and, therefore, should be encouraged and promoted by public and private organisations. The idea of innovation came to substitute the pure vs. applied science dichotomy that had dominated government development policies before WWII. After the 1957 Sputnik crisis, the American government began to funnel a considerable amount of resources (funding, for example, what would become DARPA) not only to enhance basic science but also to conduct research in creativity. Technology came to be seen not only as the application of theoretical science but as the product of creativity and entrepreneurial spirit. By the 1960s the policy-making doctrine in the West had recognised that scientific research by itself 
could not provide direct and tangible (a.k.a. profitable) answers to pressing problems, something else was required. Innovation thus came to be equated to technological invention or change, preferably one that could be immediately commercialised.

Vinsel's objection against IDEO-DT's somewhat liberal use of the term "innovation" tacitly appeals to the chasm that exists between a truly innovative technological system, say railroads or the Internet, vs. something like the now-defunct "Juicero" or the "Fyre Festival" fiasco [15]. Whereas the first examples have led to lasting and profound socioeconomic, political, cultural, and environmental changes, the latter turned at best into cautionary tales about the perils of twenty-first-century start-up culture.

Vinsel's second objection concerns the proposition that IDEO-DT could become the core of (a new strain of) liberal arts. This idea relates to the notion that design is an independent epistemic system midway between the sciences and the humanities. Vinsel's criticism is mainly informed by Miller's (2018) article, "Is 'Design Thinking' the New Liberal Arts?" wherein the latter ponders the potential benefits of applying the d.schools "antiestablishment" (i.e. unstructured) approach to design methods in education at large. Although seemingly seduced by the d.school's ideas, Miller is nonetheless careful to critique the way IDEO literature eschews virtually all "serious consideration on 'pastness'" in favour of present-tense problemsolving. However, neither Miller nor Vinsel seem to be aware that the characterisation of design as a liberal art precedes the foundation of the d.school for several years. And furthermore, that an influential strain of management theory portrays management as both a liberal art (Peter Drucker) and as design (Peter Senge) (see Dunne \& Martin, 2006; and LoRusso, 2017).

In an article titled Wicked Problems in Design Thinking, Buchanan (1992, p. 5) contends design "should be recognized as a new liberal art of technological culture". For him, a liberal art provides above all an "integrated understanding of human experience" and, seen under such terms, the hypothetic role of design would be to "integrate useful knowledge from the arts and the sciences alike" (1992, p. 6). Buchanan draws heavily on John
Dewey's (pragmatist) understanding of "technology" as an "art of experimental thinking" (1992, p. 8). By "liberal art" Buchanan explicitly means a "discipline of thinking" that may be shared by everyone, and that could be mastered by a few individuals "with distinctive insight". In other words, Buchanan is reframing the kind of literacy, or rather "design awareness", that Archer (1979, p. 20) had envisioned a decade before. Both Archer and Buchanan regard Design as an "architectonic" field capable of providing a type of insight that is not accessible to traditional humanistic or scientific disciplines: something akin to a "maker's knowledge", wherein practical and theoretical knowhow complement each other to reach "full and useful episteme" (see Floridi, 2011, p. 288).

Archer's and Buchanan's idealised future for design education is far removed from the reality of IDEO-DT training, with its emphasis on instant and painless results. While hardly anyone would object to people of all ages having a minimum of design literacy, Vinsel's and Jen's critique encourages us to look beyond IDEO-DT for inspiration to build what could become a new maker's discipline. One that genuinely reflects the complexities and depth of the new old learning that proper design offers.

\section{6 | CONCLUSIONS AND IMPLICATIONS}

Admittedly, Jen's and Vinsel's criticism of IDEO-DT is blunt and incomprehensive, for neither care to describe DT methodology in depth. Nonetheless, beyond the name-calling, both have managed to touch on key aspects that reveal why IDEO-DT should perhaps come under more thorough scrutiny. Jen did not explain what she understands by "bullshit", however most likely she was using the term in its most common everyday meaning of "nonsense".

A simple skimming of IDEO-DT publications shows that it is filled with jargon which is rarely clarified by its authors. Such type of obfuscation partially meets Cohen's criteria of "unclarifiable unclarity"; but it would be an exaggeration to say that everything about IDEO-DT is nonsense. By implicitly promoting the notion that IDEO-DT is all there is to "design thinking", and hence disregarding the truth, the d.school might be engaging in the more morally questionable Frankfurt bullshit. However, whether the promoters of IDEO-DT have failed to acknowledge the history and legacy of design 
methods out of ignorance, self-deception, or lack of interest is impossible to know. Having such lame reasons for engaging in bullshit meets Kimbrough's criteria, but it would be impossible to generalise the judgement. And yet, at least some of the ideas advanced by IDEO-DT do have their roots in design research. These reasons, along with the fact that bullshit itself remains a contested notion, mean that one must suspend judgement on whether everything about IDEO-DT can be dismissed as bullshit.

The above conclusion illustrates why name-calling rarely (if ever) leads to fruitful scholarly exchanges, more so when the whole point of the expletive is to marginalise the subject and exclude it from serious discussion. The goal of this paper has been to show precisely why critical analysis of IDEO-DT needs to go beyond derision. This is not to say that denouncing bullshit is not a moral imperative, particularly in the age of exponential growth of information warfare. But perhaps, rather than just mocking the tasteless echo chamber of the five-step design process and the way advocates of IDEO-DT idolise Post-it notes, we should focus on making true design literacy more available. That is, promoting an understanding of the history, complexity, and potential of design outside the d.school's box.

Throughout this paper, we have seen that both design thinking and bullshit are far from being homogeneous concepts. Hence, to determine whether Jen's and Vinsel's criticism held it was first necessary to determine which kind of DT they were referring to and what could be understood by bullshit in the first place. Their critique has served as an opportunity to show how IDEO-DT has hijacked the meaning of design thinking and, as a result, many complex ideas underpinning design methodology have been washed off, forgotten, or supplanted by business jargon. In the eyes of those who stumble upon IDEO-DT and d.school literature, and who possess little or no knowledge of the rich history of design research, this methodology (depending on their leanings) appears as a seductive tool or as yet another management fad. Unbeknownst to them, is the fact that "traditional" DT represents, to borrow Buchanan's words, a sincere attempt to recognise and elevate the dignity and importance, not only of design but of maker's knowledge in general. Such a state of affairs calls for a deeper and broader critique of IDEO-DT and the concepts it promotes (such as innovation and creativity). Not only because it trivialises an entire human discipline, but also to reclaim the actual contributions that design, as an epistemic system, can bring to other domains of human activity. Part of this strategy could perhaps involve steering away from the idea that there is a designerly way of thinking and focus instead on proving why designers, like other "doers", create practical knowledge.

\section{ACKOWLEDGMENTS}

I want to thank all the members of the $x C o A x$ organising committee and the editors of this special issue for helping me in turning this article into readable form. In particular, I would like to thank Luísa Ribas for her thoughtful comments and guidance.

\section{ENDNOTES}

[1] Despite receiving considerable criticism, Jen has persisted on her criticism (see Jen, 2018).

[2] The human potential movement.

[3] Vinsel cites a recent article in which history professor, Peter N. Miller (2018), discusses precisely that possibility.

[4] As well as a commercial and popular success. As Hardcastle \& Reisch (2006) note, despite being a typical, unassuming academic work, the book rose to the New York Times' bestseller list, where it remained for twenty-six weeks.

[5] The disagreements concerning the origins of design have much to do with the way design itself is conceived by different authors. A vital tension is how to distinguish the craftsperson from the designer (Parsons, 2015, sec. 1.4).

[6] Whereas design theory is mainly concerned with the practice of Design, philosophy of design is concerned with Design and its specific aims and problems "in light of the fundamental questions that philosophy examines: questions about knowledge, ethics, aesthetics and the nature of reality" (Parsons, 2015, Introduction).

[7] Reading Tim Brown's book, Change by Design (2009, Introduction), one gets the impression that the very concept of design thinking emerged in the early 2000s during a casual conversation between him and Kelley. 
[8] This epistemic middle-ground echoes C.P. Snow's account of the "Two Cultures" (1959/2012), as well as his latter, more conciliatory characterisation of the "third culture" (1963/2012).

[9] Archer (1979, p. 17) characterises design problems as "ill-defined", more or less following Horst Rittel's (1973) concept of "wicked problems", i.e. the kind in which there is no consensus about the definition of the problem itself nor its solution. For thorough discussions of wicked problems see Churchman (1967) and Coyne (2005).

[10] Cross's statement resembles Clement Greenberg's (1940/1999) quintessentially modernist defence of the "purity" of the artistic medium.

[11] It is important to note that Cross partially builds this argument on Howard Gardner's (1983/2011) "theory of multiple intelligences".

[12] Arguably, IDEO-DT's emphasis on empathy can be traced back to the ideas of management theorists such as Douglas McGregor, Abraham Maslow, or Robert Greenleaf (for an overview see LoRusso, 2017).

[13] For a lengthy discussion on this problem see Galle (2011) and Parsons (2015, sec. 2.3).

[14] The rationale for doing so is best summarised in the following quote: "design thinking involves a commitment of participants and facilitators to discouraging criticism in product development interaction [...] Deferring adverse judgments has been argued to fundamentally help improve creativity in idea generation processes" (Reimann \& Schilke, 2011, p. 53).

[15] The Juicero was a USD $700 \mathrm{Wi-Fi}$ enabled juicer that worked exclusively with pre-packaged bags of fruits and vegetables. Highly criticised since it was first released into the market, the Juicero was revealed as an unnecessarily complex device after a youtuber showed how he could squeeze the juice out of the bags with his bare hands. The "Fyre Festival" was a luxury music festival for which attendees had to pay thousands of dollars but was eventually cancelled after multiple irregularities. The organisers faced multimillion lawsuits and at least one of them was sentenced to prison.

\section{REFERENCES}

Archer, B. (1979). Design as a discipline. Design Studies, 1(1), 17-20. https://doi.org/10.1016/0142$694 \times(79) 90023-1$

Black, M. (1982). The prevalence of humbug. Philosophic Exchange, 13(1). Article 4. Retrieved from

https://digitalcommons.brockport.edu/phil_ex/vol13/i ss $1 / 4$

Brown, T. (2008). Design thinking. Harvard Business Review, 85-92. Retrieved from https://hbr.org/2008/06/design-thinking

Brown, T. (2009). Change by design: How design thinking transforms organizations and inspires innovation. New York; London: Harper Collins ebooks.

Buchanan, R. (1992). Wicked problems in design thinking. Design Issues, 8(2), 5. https://doi.org/10.2307/1511637

Buchanan, R. (2001). Design research and the new learning. Design Issues, 17(4), 3-23. https://doi.org/10.1162/07479360152681056

Churchman, C. W. (1967). Guest editorial: Wicked problems. Management Science, 14(4), B141-B142. https://doi.org/10.1287/mnsc.14.4.B141

Cohen, G. A. (2002). Deeper into bullshit. In S. Buss \& L. Overton (Eds.), Contours of agency: Essays on themes from Harry Frankfurt (pp. 321-339). Cambridge, Massachusetts; London: The MIT Press.

Coyne, R. (2005). Wicked problems revisited. Design Studies, 26(1), 5-17. https://doi.org/10.1016/j.destud.2004.06.005

Cross, N. (1982). Designerly ways of knowing. Design Studies, 3(4), 221-227. https://doi.org/10.1016/0142-694x(82)90040-0

Cross, N. (2001). Designerly ways of knowing: Design discipline versus design science. Design Issues, 17(3), 49-55. https://doi.org/10.1162/074793601750357196

Cross, N. (2006). Designerly ways of knowing. Germany: Springer-Verlag. https://doi.org/10.1007/184628-301-9 
Cross, N. (2011). Design thinking: Understanding how designers think and work. Oxford; New York: Berg.

Dunne, D., \& Martin, R. (2006). Design thinking and how it will change management education: An interview and discussion. Academy of Management Learning \& Education, 5(4), 512-523. https://doi.org/10.5465/amle.2006.23473212

Floridi, L. (2011). A defence of constructionism: Philosophy as conceptual engineering. Metaphilosophy, 42(3), 282-304. https://doi.org/10.1111/j.1467-9973.2011.01693.x

Frankfurt, H. (2005). On bullshit. New Jersey; Oxford: Princeton University Press. (Original work published 1986)

Galle, P. (2002). Philosophy of design: An editorial introduction. Design Studies, 23(3), 211-218. https://doi.org/10.1016/s0142-694x(01)00034-5

Galle, P. (2011). Foundational and instrumental design theory. Design Issues, 27(4), 81-94. https://doi.org/10.1162/desi_a_00107

Gardner, H. (2011). Frames of mind: The theory of multiple intelligences (3rd ed.). New York: Basic Books. (Original work published 1983)

Godin, B. (2008). Innovation: The history of a category (Working paper No. 1). Montréal: Project on the Intellectual History of Innovation. Retrieved from http://www.csiic.ca/PDF/IntellectualNo1.pdf

Godin, B. (2014). Innovation and creativity: A slogan, nothing but a slogan (Working paper No. 18). Montréal: Project on the Intellectual History of Innovation. Retrieved from http://www.csiic.ca/PDF/CreativityEnglish.pdf

Godin, B. (2015). Innovation contested: The idea of innovation over the centuries. New York; London: Routledge. https://doi.org/10.4324/9781315855608

Graeber, D. (2015). The utopia of rules: On technology, stupidity, and the secret joys of bureaucracy. Brooklyn; London: Melville House.

Greenberg, C. (1999). Towards a newer Laocoön. In C. Harrison \& P. Wood (Eds.), Art in theory 19001990: An anthology of changing ideas (12th reprint, pp. 554-560). Oxford, UK: Blackwell Publishing. (Original work published 1940)
Hardcastle, G. L., \& Reisch, G. A. (2006). On bullshitmania. In G. L. Hardcastle \& G. A. Reisch (Eds.), Bullshit and philosophy. Chicago: Open Court.

Jen, N. (2017). Design thinking is bullshit [Talk]. Retrieved 2 September 2018, from http://99u.com/videos/55967/natasha-jen-designthinking-is-bullshit

Jen, N. (2018, August 21). Graphic designer Natasha Jen poses six questions for design thinkers [Talk]. Retrieved 5 October 2018, from http://www.designindaba.com/videos/conferencetalks/graphic-designer-natasha-jen-poses-sixquestions-design-thinkers

Kimbrough, S. (2006). On letting it slide. In G. L. Hardcastle \& G. A. Reisch (Eds.), Bullshit and philosophy. Chicago: Open Court.

Lawson, B. (2005). How designers think: The design process demystified (4th ed.). Oxford; Burlington: Architectural Press.

LoRusso, J. D. (2017). Spirituality, corporate culture, and american busines: The neoliberal ethic and the spirit of global capital. London; New York: Bloomsbury Academic.

Love, T. (2000). Philosophy of design: A metatheoretical structure for design theory. Design Studies, 21(3), 293-313. https://doi.org/10.1016/s0142-694x(99)00012-5

Miller, P. N. (2018, March 26). Is 'design thinking' the new liberal arts? Retrieved 2 September 2018, from https://www.chronicle.com/article/ls-DesignThinking-the-New/228779?cid=at

Parsons, G. (2015). The philosophy of design. Cambridge; Malden: Polity Press.

Peck, J. (2010). Constructions of neoliberal reason. Oxford; New York: Oxford University Press.

Reimann, M., \& Schilke, O. (2011). Product differentiation by aesthetic and creative design: A psychological and neural framework of design thinking. In H. Plattner, C. Meinel, \& L. Leifer (Eds.), Design thinking: Understand - improve - apply (pp. 45-57). Springer Berlin Heidelberg. https://doi.org/10.1007/978-3-642-13757-0_3 
Rittel, H. W. J., \& Webber, M. M. (1973). Dilemmas in a general theory of planning. Policy Sciences, 4(2), 155-169. https://doi.org/10.1007/bf01405730

Rowe, P. G. (1991). Design thinking. Cambridge; London: The MIT Press. (Original work published 1986)

Snow, C. (2012). The rede lecture. In The two cultures (15th Reprint, pp. 1-51). UK: Cambridge University Press. (Original work published 1959)

Snow, C. (2012). The two cultures: A second look. In The two cultures (15th Reprint, pp. 53-100). UK: Cambridge University Press. (Original work published 1963)

Spicer, A. (2017, November 23). From inboxing to thought showers: How business bullshit took over. Retrieved 2 September 2018, from https://www.theguardian.com/news/2017/nov/23/fro m-inboxing-to-thought-showers-how-businessbullshit-took-over

Vinsel, L. (2017, December 6). Design Thinking is Kind of Like Syphilis-It's Contagious and Rots Your
Brains. Retrieved 3 September 2018, from https://medium.com/@sts_news/design-thinking-iskind-of-like-syphilis-its-contagious-and-rots-yourbrains-842ed078af29

\section{BIOGRAPHICAL INFORMATION}

Rodrigo Hernández-Ramírez studied communication, design \& visual communication, and philosophy of science in his native Mexico City. Having worked as a designer and front-end developer, he holds an MA in multimedia art with a specialisation in photography from the University of Lisbon, where he also obtained a PhD in fine arts with specialisation in multimedia art. $\mathrm{He}$ is a collaborator at the Centre for Research and Studies in Fine Arts (CIEBA) at the same institution. Currently, he teaches design methodology at the Instituto de Arte, Design e Empresa (IADE), in Lisbon. His research interests stand at the intersection of philosophy of technology, design, and new media art. $\mathrm{He}$ is particularly interested in human-technology relations and how technologies shape the way we understand the world and ourselves. 